\title{
New Sudanese Reference Chart of Fetal Biometry and Weight Using Ultrasonography
}

\author{
Caroline Edward Ayad1, Ahmed Abdelrahim Mohammed Ibrahim², \\ Mohammed Elfadil Mohammed GarElnabi1, Bushra Hussein Ahmed ${ }^{3}$, \\ Elsafi Ahmed Abdalla1, Mohammed Ahmed Elshiekh Saleem ${ }^{1}$ \\ ${ }^{1}$ College of Medical Radiological Science, Sudan University of Science and Technology, Khartoum, Sudan \\ ${ }^{2}$ Faculty of Radiology Science and Medical Imaging, Alzaiem Alazhari University, Khartoum, Sudan \\ ${ }^{3}$ College of Medical Radiological Science and Nuclear Medicine, The National Rabat University, Khartoum, Sudan \\ Email: carolineayad@yahoo.com
}

Received 16 May 2016; accepted 18 June 2016; published 21 June 2016

Copyright (C) 2016 by authors and Scientific Research Publishing Inc.

This work is licensed under the Creative Commons Attribution International License (CC BY). http://creativecommons.org/licenses/by/4.0/

(c) (7) Open Access

\begin{abstract}
Background: Many centers in Sudan use the reference data for fetal biometry. The recently published population-based reference either overestimated or underestimated the weight of the fetuses. Objective: To establish a national reference for fetal biometry, and weight by gestational age for singleton fetuses in Sudan. Methods: Data were collected on all singleton live births documented in the data collection sheet done at Saudi Hospital from 2015 to 2016 (n = 225). Gestational age estimation was based on the last menstrual period and fetal ultrasound thereafter. Fetal biometry and weight and other 6 fetal weight formulae were assessed. Reference data for fetal growth by gestational age were created. Results: New charts and reference equations are reported in Sudanese population for fetal biparietal diameter, head circumference, abdominal circumference and femur length and fetal weight. Conclusion: We advocate that these reference charts and equations for fetal biometry and weight might be valuable in the clinical use for appropriate ethnic Sudanese.
\end{abstract}

Keywords

Fetal Biometry, Fetal Weight, Gestational Age, Ultrasonography

\section{Introduction}

Reference data for birth weight, fetal biometry were first published in the 1970 [1] [2] and revised on a regular

How to cite this paper: Ayad, C.E., Ibrahim, A.A.M., GarElnabi, M.E.M., Ahmed, B.H., Abdalla, E.A. and Saleem, M.A.E. (2016) New Sudanese Reference Chart of Fetal Biometry and Weight Using Ultrasonography. Open Journal of Radiology, 6, 131139. http://dx.doi.org/10.4236/ojrad.2016.62020 
basis subsequently [3]-[9]. The anthropometric reference curves formulated by Usher and McLean [2] are still in use in some departments [10].

Ultrasound examination and measurement of fetal biometry have become an integral part of recent obstetric care. These measurements can serve for measuring the gestational age (GA) or assessment of fetal development. Selection of the appropriate reference charts is of great importance to ensure accurate diagnosis. Some published reference charts are blemished [11]. Appropriate methods have been published [11] [12] and fetal biometry charts and equations for various populations are now available in the open literature [13]-[18]. It is well known that ethnicity has a significant influence on fetal biometry [19] [20].

There are main difficulties in establishing reference growth curves for newborns: firstly, the calculation of gestational age, which together with intrauterine growth determines the birth weight. Anthropometric studies that calculate gestational age by the last menstrual period may yield systematic differences from those that use obstetric methods, such as early fetal ultrasound or neonatal examination [13]-[16] [20]. Secondly, LMP-based gestational age determinations are limited by many causes [13]. This phenomenon was very apparent on comparison of the population-based Canadian growth reference [7] with data published by Alexander and collaborators [5] in the United States and by Dolberg et al. [8] in Israel. The second challenge in establishing a reference chart is the identification and exclusion of live births with improbable values of birth weight for gestational age [18] [19].

Cross-sectional reference charts and equations from the ethnic Sudanese population using appropriate methodology have not previously been published in the open literature. The aim of this study, therefore, was to construct reference charts and equations for fetal biparietal diameter (BPD), head circumference (HC), abdominal circumference (AC) and femur length (FL) and fetal weight in the ethnic Sudanese.

\section{Materials and Methods}

\subsection{Study Population}

The data of this prospective study were obtained from 225 Sudanese pregnant ladies with uneventful pregnancies (Normal); attending the designated study area during the study period (December 2015-March 2016), with singleton pregnancies at second and third trimester with viable fetus. Pregnancies with established diagnosis of hypertension, diabetes were excluded. Mean maternal age/years (27.15 \pm 5.86$)$, weight/Kg (79.32 \pm 10.39$)$, height/cm (164.67 \pm 5.65$)$, BMI (2.93 \pm 0.37$)$, parity ( $2.66 \pm 1.69)$. Verbal consent was firstly obtained from all potential participants. The aims, benefits of the present study were explained to all participants in details. Medical, obstetric and gynecological history of all study subjects posing as (sample) were thoroughly reviewed directly from participants themselves and those with conditions that may in any way, alter the findings of the current study were excluded.

\subsection{Measuring of Fetal Weight}

Sonographic examination was obtained for all participants (225 pregnant ladies) in supine position using Ultrasound machine with curvilinear probe and transducer frequency of $3.5 \mathrm{MHz}$. The procedures were explained for participants before the scanning. Singleton pregnancy of (60 fetuses out of 225), were included on the study to measure their fetal weights after delivery using weight caliber. Fetuses with congenital anomalies, the biometric measurements of those, which were unable to ascertain due to reasons like deeply engaged head, were excluded from the study. Biparietal diameter (BPD) measurement was taken from the outer edge of the fetal proximal skull bone to the inner edge of the distal bone. The head circumference (HC) was calculated using electronic ellipse available on the ultrasound scanner. The fetal abdominal circumference (AC) was measured in standard transverse planes at the levels of the stomach and umbilical vein-ductus venous complex. The femur length (FL) was measured from the proximal end of the greater trochanter to the distal metaphysis. Gestational age and fetal weight were calculated. Estimated fetal weight from each equation was calculated separately using basic biometric values for estimation of fetal weight measured automatically by the ultrasound machine. The fetal biometric measurements which were taken previously for the planned delivery were collected in a data sheet. The actual birth weights for 60 babies out of 225 fetuses were also entered into the data sheet after the delivery of the fetuses. With the collected measurements done by ultrasound machine and the estimated measurement done for every fetus, 6 different EFWs formulae (Hadlock et al., I, П, Ш, 1V, Campbell and Sheppard) [21] were tested. 
The validity of these 6 formulas in predicting the actual FW in the study population was tested after comparison with the actual fetal weights. The fetal biometry necessary for measuring the fetal weight was as follows \{Sheppard (BPD, AC), Campbell (AC), Hadlockl-(AC, FL), Hadlock II (BPD, AC, FL), Hadlock III (HC, AC, FLx HC), Hadlock IV (BPD, HC, AC, FL)\} [22]. Actual birth weights of all the fetuses were taken separately. The birth weights were measured by trained nurse.

\subsection{Data Analyses}

Data were analyzed using Statistical Package of Social Sciences (SPSS) (Inc., Chicago, Illinois version 16). The data obtained were analyzed statistically by computing descriptive statistics: Mean, \pm SD values and percentages. Paired t-test was used for testing the differences between the formulae results. The difference at value of $\mathrm{p}<$ 0.05 will be considered significant.

\section{Discussion}

Ultrasonography is routinely used to estimate the fetal weight and is often used as a proxy to actual birth weight. Many ultrasound estimated fetal weight (EFW) formulae have been designed and these are based on different fetal biometric parameters [23] [24]. Use of ultrasound in predicting birth weight is more precise in early gestations, however at term there is significant worsening due to fluid to fetus ratio reduction, bony structures become increasingly calcified, and the vertex descends in the pelvis, making measurements of head circumference and biparietal diameter more difficult [25]. There is no systematic evaluation of the established ultrasound EFW in predicting actual birth weights in the Sudanese population.

Therefore the aim of this study was to test 6 common applied fetal weight formulae and validate the established EFW formulae depending on the dating of gestational age to predict actual birth weight in Sudanese pregnant ladies as well as to provide reference equations for biometric measurements. The data were collected for the purposes of this study rather than being obtained from an available clinical dataset. Data for the study were obtained from only one designated ultrasound examination from each lady. Pregnancies complicated with congenital abnormalities were excluded. Mean and standard deviation of the fetal biometric measurements taken from 225 fetuses were presented in (Table 1).

Numerous formulae have been published for the purpose of estimating fetal weight from a variety of sonographically obtained biometric measurements. Biparital diameter (BPD), head circumference (HC), Abdomen circumference (AC) and femur length (FL), most commonly, a combination is used [26] [27]. An accurate means of estimating fetal weight using ultrasonography was first described by Campbell 1975 [26]. The most popular formulae are Sheppard, Warsof's [28] with Sheppard's modification [29] and Hadlock [27] [30]. These formulae are included in most ultrasound equipment packages, even though Sonographic machines offer various different formulae for estimation of fetal weight. Table 2 presented the new established equation that was applied to estimate the Sudanese fetuses' weights. Table 3 presented the estimated fetal weight which was evaluated using six formulae as well as the measured weight for Sudanese and was classified according to GA. Figures 1-4 show the positive linear relationship between the gestational age/weeks and $\mathrm{BPD} / \mathrm{cm}, \mathrm{FL} / \mathrm{cm}$, $\mathrm{HC} / \mathrm{cm}$ and $\mathrm{AC} / \mathrm{cm}$. The biometric measurements increased significantly/week for Sudanese fetuses at $\mathrm{p}=0.000$. The contribution of the FL scores the highest values on predicting the GA constituting $99 \%$ in both the second and third trimesters.

Table 1. Mean and standard deviation of the fetal Biometric measurements \{biparietal diameter (BPD), the head circumference (HC), abdominal circumference (AC), femur length (FL)\}, Gestational age and Estimated Fetal Weight/Kg measured by Ultrasound Machine.

\begin{tabular}{ccccccc}
\hline & \multicolumn{7}{c}{ Fetal Biometric Measurements } & & \\
& $\begin{array}{c}\text { BPD } \\
(\mathbf{c m})\end{array}$ & $\begin{array}{c}\text { FL } \\
\mathbf{( c m )}\end{array}$ & $\begin{array}{c}\text { HC } \\
(\mathbf{c m})\end{array}$ & $\begin{array}{c}\text { AC } \\
(\mathbf{c m})\end{array}$ & $\begin{array}{c}\text { Gestational } \\
\text { Age/Weeks }\end{array}$ & $\begin{array}{c}\text { Estimated Fetal } \\
\text { Weight/Kg measured by } \\
\text { Ultrasound Machine }\end{array}$ \\
\hline Mean & 8.16 & 6.25 & 3.01 & 2.71 & 32.51 & 2.09 \\
Standard deviation & \pm 1.60 & \pm 1.39 & \pm 0.53 & \pm 0.59 & \pm 6.17 & \pm 1.04 \\
\hline
\end{tabular}


Table 2. Shows the Correlations Coefficients between the New estimation method for fetal weight/Kg measurement (Dependant variable) and the measured GA and HC for Sudanese.

\begin{tabular}{ccccc}
\hline \multirow{2}{*}{ Model } & \multicolumn{2}{c}{ Unstandardized Coefficients } & Sig. \\
\cline { 3 - 5 } & & $\mathrm{B}$ & $\mathrm{t}$ & 0.000 \\
(Constant) & -2.848 & -29.269 & 0.000 \\
GA & 0.211 & 17.139 & 0.000 \\
HC & -0.634 & -4.528 & \\
\hline
\end{tabular}

The New established equations For Sudanese are as follows: EFW $_{\mathrm{GAHC}}=\{(-2.848)+(0.211 \times \mathrm{GA})+(-0.634 \times \mathrm{HC})\}$.

Table 3. Mean and standard deviation of the estimated fetal weight measured for 225 singleton pregnant ladies and evaluated by the (FW formulae) and the New Method For Fetal weight estimation (EFW $\mathrm{GAHC}_{\mathrm{C}}$.

\begin{tabular}{|c|c|c|c|c|c|c|c|}
\hline & \multicolumn{6}{|c|}{ The Six Tested Formulae For Fetal weight estimation } & \multirow{2}{*}{$\begin{array}{c}\text { New Method } \\
\text { For Fetal weight } \\
\text { estimation } \\
{ }^{*} \text { EFW_GAHC }\end{array}$} \\
\hline & Campbell & Sheppard & Hadlock I & Hadlock П & Hadlock Ш & Hadlock IV & \\
\hline Mean & 3.69 & 3.17 & 2.59 & 2.67 & 2.41 & 1.53 & 2.11 \\
\hline Std. Deviation & 0.16 & 0.27 & 0.27 & 0.28 & 0.23 & 0.25 & 0.98 \\
\hline
\end{tabular}

*A positive correlation was found between EFW_GAHC using our new formula and the actual BWs of 60 newborn babies. The correlation is significant at $\mathrm{p} \leq 0.005$.

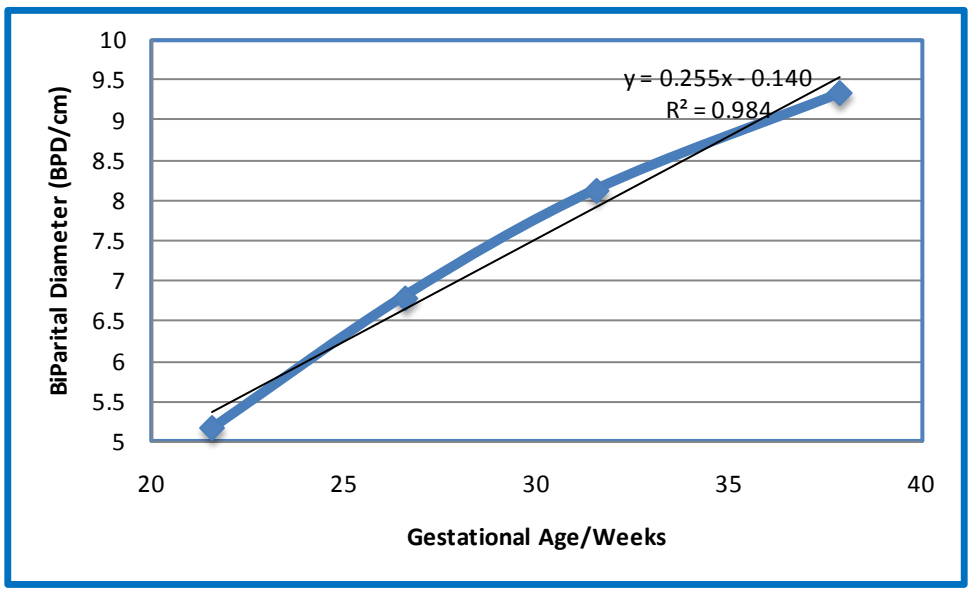

Figure 1. Scatter plot diagram that shows the positive linear relationship between the gestational age/weeks and $\mathrm{BPD} / \mathrm{cm}$ the BPD increased by 0.26 $\mathrm{cm} /$ week for Sudanese fetuses. The contribution of the BPD on predicting of the $\mathrm{GA}$ is $98 \%$. $\mathrm{R}^{2}=0.984, \mathrm{p}=0.000$.

Our sample including a gestational age between 21.55 and 37.85 weeks of gestation and fetal reference charts for usage among the Sudanese population was established (Figures 1-4). Our study has established new equation and chart for sonographic evaluation of the sudanese fetal weight as presented in Table 2 and Table 4. Other studies previously indicated that size charts should not be used for dating pregnancies, and accurate dating requires consideration of gestational age as a function of fetal size [31].

It is well known that ethnicity has a significant influence on fetal biometry [19] [20] as well as small for gestational age carries a higher risk of various adverse outcomes in the perinatal period [32]-[37]. This is why it is important to establish a reference chart for measuring the GA and fetal weight for Sudanese. Precise estimation of fetal weight is the goal in the clinical practice. In the current study, fetal weight estimation using 6 formulae 


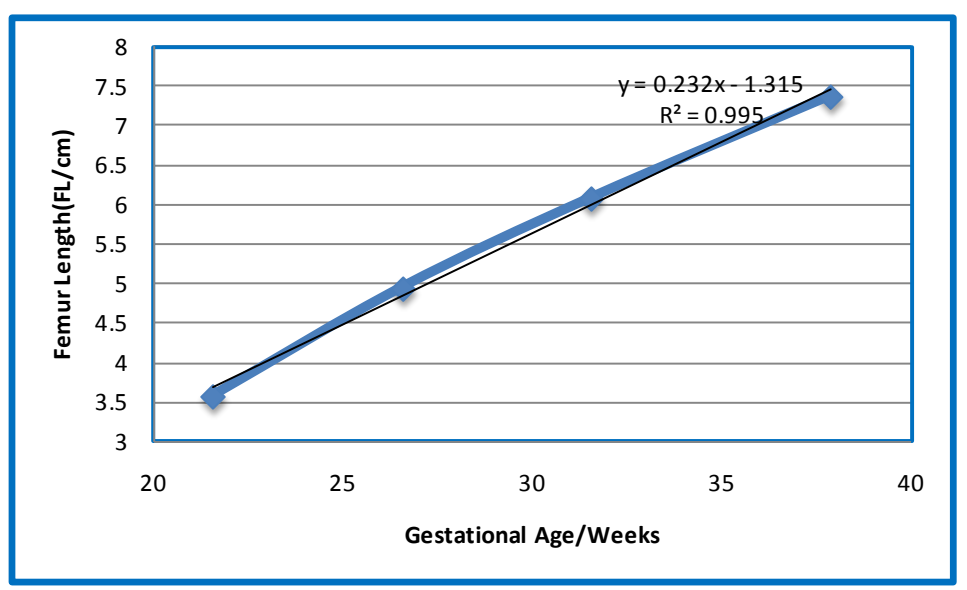

Figure 2. Scatter plot diagram that shows the positive linear relationship between the gestational age/weeks and FL/cm. The FL increased by $0.23 \mathrm{~cm} /$ week for Sudanese fetuses. The contribution of the FL on predicting of the GA is $99 \% \mathrm{R}^{2}=0.995, \mathrm{p}=0.000$.

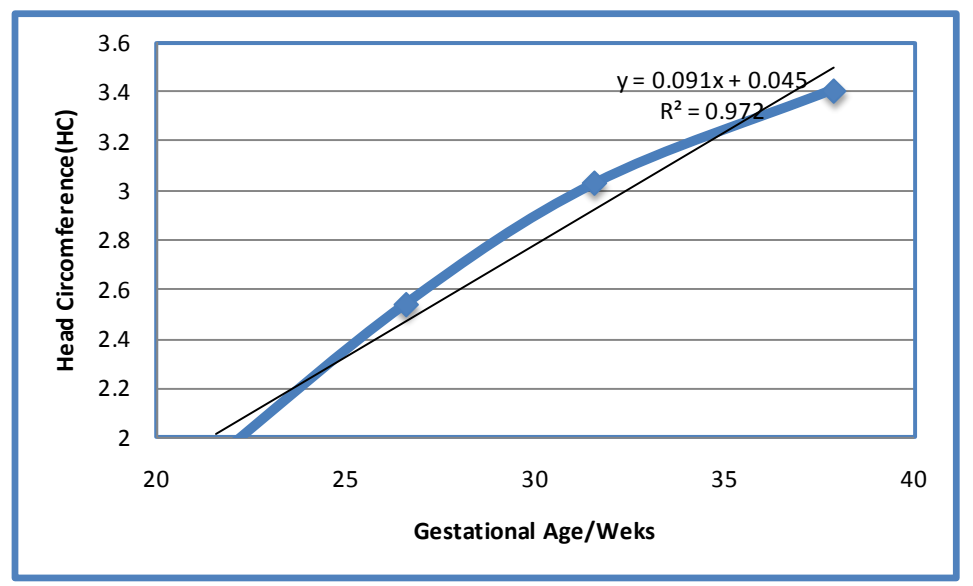

Figure 3. Scatter plot diagram that shows the positive linear relationship between the gestational age/weeks and HC/cm. The HC increased by $0.09 \mathrm{~cm} /$ week for Sudanese fetuses. The contribution of the $\mathrm{HC}$ on predicting of the GA is $97 \% \mathrm{R}^{2}=0.972, \mathrm{p}=0.000$.

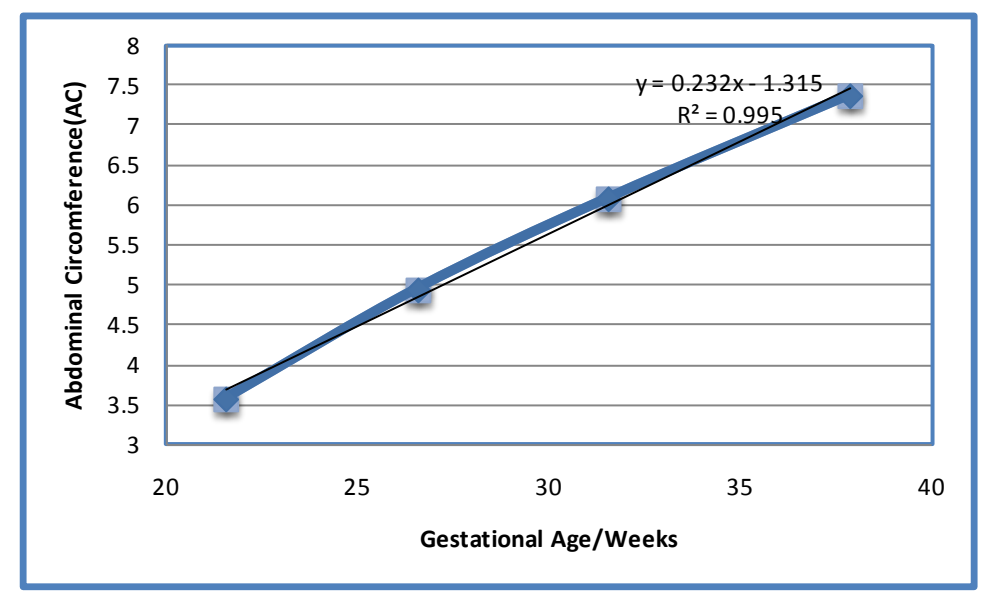

Figure 4. Scatter plot diagram that shows the positive linear relationship between the gestational age/weeks and AC/cm. The AC increased by $0.23 \mathrm{~cm} /$ week for Sudanese fetuses. The contribution of the AC on predicting of the GA is $99 \% \mathrm{R}^{2}=0.995, \mathrm{p}=0.000$. 
Table 4. New Chart for the Sudanese fetal weight measured by (Fetal birth weight estimation Formulae: Campbell, Sheppard, Hadlock I, Hadlock II, Hadlock III, Hadlock IV) and EFW/Kg measured by ultrasound machine and the new established equation $\left(\mathrm{EFW}_{\mathrm{GAHC}}\right)$ for Sudanese weight measurements classified into classes according to gestational age (GA), $\mathrm{R}^{2}$ and $\mathrm{p}$ value.

\begin{tabular}{cccccccccc}
\hline \multicolumn{7}{c}{ New Chart for the Sudanese fetal weight } \\
\hline GA/weeks & Campbell & Sheppard & Hadlock I & Hadlock II & Hadlock III & Hadlock IV & EFW & EFW_GAHC \\
\hline 21.5 & 4.0148 & 2.6592 & 2.06 & 2.1328 & 1.964 & 1.0452 & 0.4442 & 0.408201 \\
26.55 & 3.8315 & 2.9387 & 2.3356 & 2.4151 & 2.1946 & 1.2967 & 0.9839 & 1.097717 \\
31.55 & 3.6849 & 3.1653 & 2.5612 & 2.6474 & 2.3842 & 1.5021 & 1.8455 & 1.897938 \\
37.85 & 3.5692 & 3.3676 & 2.8094 & 2.8943 & 2.5919 & 1.7288 & 2.9615 & 2.938063 \\
$\mathbf{R}^{2}$ & 0.976 & 0.984 & 0.993 & 0.993 & 0.994 & 0.994 & 0.998 & 0.998 \\
$\mathbf{p}$ & 0.000 & 0.000 & 0.000 & 0.000 & 0.000 & 0.000 & 0.000 & 0.000 \\
\hline
\end{tabular}

*Fetuses weight ranged between 1.86 to $3.987 \mathrm{Kg}$.

based on the fetal biometric measurements (BPD or HC, FL, and AC) that was used on most of the biometry were tested. Birth weight is influenced by maternal ethnicity [20] but to the best of our knowledge no data are available for Sudanese fetal weight measured by pregnancy dating for determination of fetal/birth weight according to GA. Table 2 presented the new method for fetal weight estimation for Sudanese: The New established equation is as pursues:

$$
\mathrm{EFW}_{\mathrm{GAHC}}=\{(-2.848)+(0.211 \times \mathrm{GA})+(-0.634 \times \mathrm{HC})\}
$$

The tested formulae with EFW/Kg measured for 225 fetuses by ultrasound machine, showed significant relations at $\mathrm{p} \leq 0.005$ as seen in Table 4 .

Results of assessment of the fetal weight formulae showed that the significant highest positive significant correlation between the fetal weight and GA was seen in the weight estimated by ultrasound machine and our new established equation EFW GAHC. $_{\text {. }}\left(\mathrm{R}^{2}=0.998\right.$ at $\left.\mathrm{p} \leq 0.000\right)$ followed by Hadlock III and IV equations having an equal values $\left(R^{2}=0.994\right.$ at $\left.\mathrm{p} \leq 0.000\right)$ then Hadlock II $\left(\mathrm{R}^{2}=0.993, \mathrm{p} \leq 0.000\right)$, Sheppard $\left(\mathrm{R}^{2}=0.984, \mathrm{p} \leq\right.$ $0.000)$ and lastly Campbell $\left(R^{2}=0.976, p \leq 0.000\right)$ with significant high degree of negative correlation. The New established equation $\mathrm{EFW}_{\mathrm{GAHC}}$ is the best formula identified in our study to predict Sudanese babies weight ranged between $1.86 \mathrm{Kg}$ to $3.987 \mathrm{Kg}$ (Table 4 and Figure 5).

This equation is valuable in the Sudanese babies' weight ranged between $1.86 \mathrm{Kg}$ to $3.987 \mathrm{Kg}$ and the gestational age between 21.55 and 37.85 of gestational. A positive correlation was found between $\mathrm{EFW}_{\mathrm{GAHC}}$ using our new formula and the actual BWs of 60 newborn babies. The correlation is significant at $\mathrm{p} \leq 0.005$.

In this study, the mean Estimated Fetal Weight/Kg EFW was $2.09 \mathrm{Kg} \pm 1.04 \mathrm{SD}$ and the mean Gestational Age/Weeks was 32.51weeks \pm 6.17 (Table 1). We formulate a growth formula based on ultrasound measurements for fetuses between 21.55 and 37.85 of gestational. Hadlock and colleagues also formulated an optimum growth equation based on ultrasound measurements between 10 and 41 weeks of gestation of Caucasian pregnant ladies [2] [38] but their formula was not popular as it often either under or over estimated the fetal/birth weight in other populations. In order to overcome the limitation of their study an individualized reference charts using Sudanese formula were established (Table 2 and Table 3) and the weight reference and biometry can be applicable according to the mean birth weight at 41.6 weeks of gestation for the local population using above equation. This study validates the fetal/birth weight reference derived from WHO data [39] for birth weights adapted to Sudanese. Comparing the Sudanese fetal biometry with the other populations, it showed difference with the Caucasian, French, UK, Singaporean and Chinese populations [40].

The difference in these measurements among the different populations illustrates the importance of selecting charts appropriate for one's own population.

\section{Conclusion}

In conclusion, we have constructed a new set of reference data for fetal biometric measurements and equation 


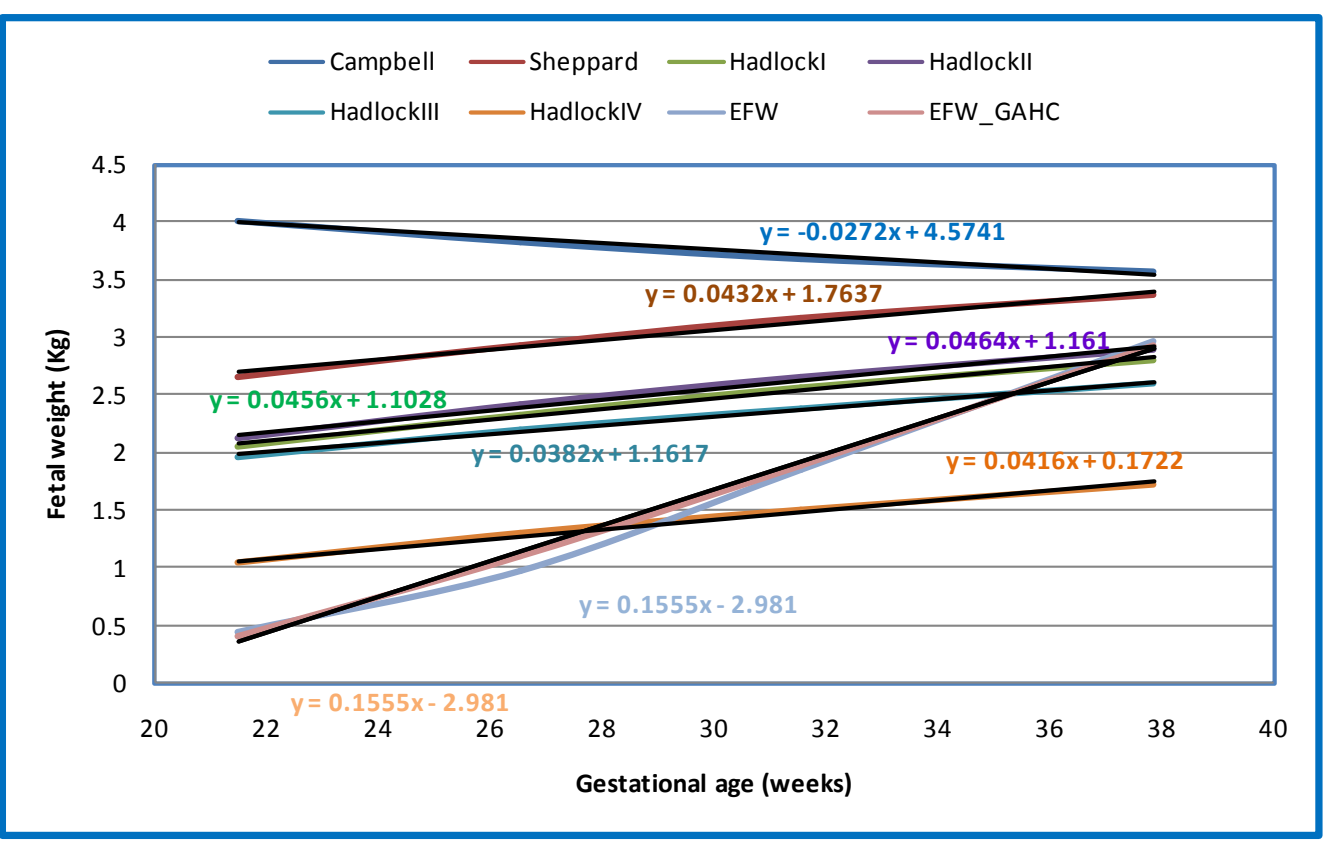

Figure 5. The linear relationship between the gestational age/weeks and fetal weight/kg estimated by 6 ultrasound formulae, ultrasound machine and the new established equation for Sudanese fetuses. $\left(\mathrm{R}^{2}\right.$ Campbell $=0.976$, Sheppard $=0.984$, Hadlock $1=0.993$, HadlockII $=0.993$, HadlockIII $=0.994$, HadlockIV $=0.994, \mathrm{EFW}=0.998, \mathrm{EFW} \_$GAHC $\left.\left.=0.998\right\}\right)$ significant at $\mathrm{p} \leq 0.000$.

for dating (GA) of pregnancy for Sudanese singleton pregnancies. We believe that our charts are ready for clinical use among appropriate ethnic Sudanese groups. We believe our newly growth references for HC might urge Sonologists to include HC measurement as a mandatory part of the routine ultrasound examination.

\section{References}

[1] Lubchenco, L.O., Hansman, C., Dressler, M. and Boyd, E. (1963) Intrauterine Growth as Estimated from Live Born Birth Weight Data at 24 to 42 Weeks of Gestation. Pediatrics, 32, 793-800.

[2] Usher, R. and McLean, F. (1969) Intrauterine Growth of Live-Born Caucasian Infants at Sea Level: Standards Obtained from Measurements in 7 Dimensions of Infants Born between 25 and 44 Weeks Gestation. The Journal of Pediatrics, 74, 901-910. http://dx.doi.org/10.1016/S0022-3476(69)80224-6

[3] Babson, S., Behrman, R. and Lessel, R. (1970) Liveborn Birth Weights for Gestational Age of White Middle Class Infants. Pediatrics, 45, 937-943.

[4] Niklasson, A., Ericson, A., Fryer, J., Karlberg, J., Lawrence, C. and Karlberg, P. (1991) An Update of the Swedish Reference Standards for Weight, Length and Head Circumference at Birth for Given Gestational Age (1977-1981). Acta Paediatrica, 89, 756-762. http://dx.doi.org/10.1111/j.1651-2227.1991.tb11945.x

[5] Alexander, G.R., Himes, J.H., Kaufman, R.B., Mor, J. and Kogan, M.A. (1996) United States National Reference for Fetal Growth. Obstetrics \& Gynecology, 87, 163-168. http://dx.doi.org/10.1016/0029-7844(95)00386-X

[6] Skjaerven, R., Gjessing, H.K. and Bakketeig, L.S. (2000) Birthweight by Gestational Age in Norway. Acta Obstetricia et Gynecologica Scandinavica, 79, 440-449. http://dx.doi.org/10.1080/j.1600-0412.2000.079006440.x

[7] Kramer, M.S., Platt, R.W., Wen, S.W., et al. (2001) A New and Improved Population-Based Canadian Reference for Birth Weight for Gestational Age. Pediatrics, 108, e35. http://dx.doi.org/10.1542/peds.108.2.e35

[8] Dolberg, S., Haklai, Z., Mimouni, F.B., Gorfein, I. and Gordon, E.S. (2005) Birth Weight Standards in the Live-Born Population in Israel. IMAJ, 7, 311-314.

[9] Karna, P., Brooks, K., Muttineni, J. and Karmasus, W. (2005) Anthropometric Measurements for Neonates, 23 to 29 Weeks Gestation, in the 1990s. Paediatric and Perinatal Epidemiology, 19, 215-226. http://dx.doi.org/10.1111/j.1365-3016.2005.00641.x

[10] Davidson, S., Sokolover, N., Erlich, A., Litwin, A., Linder, N. and Sirota, L. (2008) New and Improved Israeli Reference of Birth Weight, Birth Length,and Head Circumference by Gestational Age: A Hospital-Based Study. IMAJ, 10, 130-134. 
[11] Altman, D.G. and Chitty, L.S. (1994) Charts of Fetal Size: 1. Methodology. British Journal of Obstetrics and Gynaecology, 101, 29-34. http://dx.doi.org/10.1111/j.1471-0528.1994.tb13006.x

[12] Royston, P. and Wright, E.M. (1998) How to Construct "Normal Ranges” for Fetal Variables. Ultrasound in Obstetrics \& Gynecology, 11, 30-38. http://dx.doi.org/10.1046/j.1469-0705.1998.11010030.x

[13] Chitty, L.S., Altman, D.G., Henderson, A. and Campbell, S. (1994) Charts of Fetal Size: Head Measurements. British Journal of Obstetrics and Gynaecology, 101, 35-43. http://dx.doi.org/10.1111/j.1471-0528.1994.tb13007.x

[14] Chitty, L.S., Altman, D.G., Henderson, A. and Campbell, S. (1994) Charts of Fetal Size: Abdominal Measurements. British Journal of Obstetrics and Gynaecology, 101, 125-131. http://dx.doi.org/10.1111/j.1471-0528.1994.tb13077.x

[15] Chitty, L.S., Altman, D.G., Henderson, A. and Campbell, S. (1994) Charts of Fetal Size: Femur Length. British Journal of Obstetrics and Gynaecology, 101, 132-135. http://dx.doi.org/10.1111/j.1471-0528.1994.tb13078.x

[16] Kurmanavicius, J., Wright, E.M., Royston, P., Wisser, J., Huch, R., Huch, A. and Zimmermann, R. (1999) Fetal Ultrasound Biometry, Head Reference Values. British Journal of Obstetrics and Gynaecology, 106, 126-135. http://dx.doi.org/10.1111/j.1471-0528.1999.tb08212.x

[17] Kurmanavicius, J., Wright, E.M., Royston, P., Zimmermann, R., Huch, R., Huch, A. and Wisser, J. (1999) Fetal Ultrasound Biometry, Abdomen and Femur Length Reference Values. British Journal of Obstetrics and Gynaecology, 106, 136-143. http://dx.doi.org/10.1111/j.1471-0528.1999.tb08213.x

[18] Salomon, L.J., Duyme, M., Crequat, J., Brodaty, G., Talmant, C., Fries, N. and Althuser, M. (2006) French Fetal Biometry, Reference Equations and Comparison with Other Charts. Ultrasound in Obstetrics \& Gynecology, 28, 193-198. http://dx.doi.org/10.1002/uog.2733

[19] Yeo, G.S., Chan, W.B., Lun, K.C. and Lai, F.M. (1994) Racial Differences in Fetal Morphometry in Singapore. ANNALS Academy of Medicine Singapore, 23, 371-376.

[20] Jacquemyn, Y., Sys, S.U. and Verdonk, P. (2000) Fetal Biometry in Different Ethnic Groups. Early Human Development, 57, 1-13. http://dx.doi.org/10.1016/S0378-3782(99)00049-3

[21] Kumara, D.M.A. and Perera, H. (2009) Evaluation of Six Commonly Used Formulae for Sonographic Estimation of Fetal Weight in a Sri Lankan Population. Sri Lanka Journal of Obstetrics and Gynecology, 31, 20-33.

[22] Blair, E., Liu, Y. and Cosgrove, P. (2004) Choosing the Best Estimate of Gestational Age from Routinely Collected Population-Based Perinatal Data. Paediatric and Perinatal Epidemiology, 18, 270-276. http://dx.doi.org/10.1111/j.1365-3016.2004.00562.x

[23] Joseph, K.S., Kramer, M.S., Allen, A.C., Mery, L.S., Platt, R.W. and Wen, S.H. (2001) Implausible Birth Weight for Gestational Age. American Journal of Epidemiology, 153, 110-113. http://dx.doi.org/10.1093/aje/153.2.110

[24] Peregrine, E., O’Brien, P. and Jauniaux, E. (2007) Clinical and Ultrasound Estimation of Birth Weight Prior to Induction of Labor at Term. Obstetrics and Gynaecology, 29, 304-309. http://dx.doi.org/10.1002/uog.3949

[25] Hendler. I., Blackwell, S.C., Bujold, E., Treadwell, M.C., Wolfe, H.M., Sokol, R.J. and Sorokin, Y. (2004) The Impact of Maternal Obesity on Midtrimester Sonographic Visualization of Fetal Cardiac and Craniospinal Structures. International Journal of Obesity, 28, 1607-1611. http://dx.doi.org/10.1038/sj.ijo.0802759

[26] Campbell, S. and Wilkin, D. (1975) Ultrasonic Measurement of Fetal Abdomen C Circumference in the Estimation of Fetal Weight. British Journal of Obstetrics and Gynaecology, 82, 689-697. http://dx.doi.org/10.1111/j.1471-0528.1975.tb00708.x

[27] Hadlock, F.P., Harris, R.B., Sharman, R.S., Deter, R.L. and Park, S.K. (1985) Estimation of Fetal Weight with the Use of Head Body and Femur Measurements: A Prospective Study. American Journal of Obstetrics \& Gynecology, 75, 333-337. http://dx.doi.org/10.1016/0002-9378(85)90298-4

[28] Warsof, S.L., Gohari, P., Berkowitz, R.L. and Hobbins, J.C. (1977) The Estimation of Fetal Weight by Computer-Assisted Analysis. American Journal of Obstetrics \& Gynecology, 128, 881-892. http://dx.doi.org/10.1016/0002-9378(77)90058-8

[29] Shepard, M.J., Richards, V.A., Berkowitz, R.L., Warsof, S.L. and Hobbins, J.C. (1982) An Evaluation of Two Equations for Predicting Fetal Weight by Ultrasound. American Journal of Obstetrics \& Gynecology, 142, 47-54.

[30] Hadlock, F.P., Harrist, R.B., Fearneyhough, T.C., Deter, R.L., Park, S.K. and Rossavik, I.K. (1985) Use of Femur Length /Abdominal Circumference Ratio in Detecting the Macrosomic Fetus. Radiology, 154, 503-505. http://dx.doi.org/10.1148/radiology.154.2.3880915

[31] Altman, D.G. and Chitty, L.S. (1997) New Charts for Ultrasound Dating of Pregnancy. Ultrasound in Obstetrics \& Gynecology, 10, 174-191. http://dx.doi.org/10.1046/j.1469-0705.1997.10030174.x

[32] Ott, W.J. (1995) Small for Gestational Age Fetus and Neonatal Outcome, Reevaluation of the Relationship. American Journal of Perinatology, 12, 396-400. http://dx.doi.org/10.1055/s-2007-994506 
[33] Doctor, B.A., O’Riordan, M.A., Kirchner, H.L., Shah, D. and Hack, M. (2001) Perinatal Correlates and Neonatal Outcomes of Small for Gestational Age Infants Born at Term Gestation. American Journal of Obstetrics and Gynecology, 185, 652-659. http://dx.doi.org/10.1067/mob.2001.116749

[34] Smedler, A.C., Faxelius, G., Bremme, K. and Lagerstrom, M. (1992) Psychological Development in Children Born with Very Low Birth Weight after Severe Intrauterine Growth Retardation: A 10-Year Follow-Up Study. Acta Paediatrica, 81, 197-203. http://dx.doi.org/10.1111/j.1651-2227.1992.tb12203.x

[35] Sung, I.K., Vohr, B. and Oh, W. (1993) Growth and Neurodevelopment Outcome of Very Low Birth Weight Infants with Intrauterine Growth Retardation: Comparison with Control Subjects Matched by Birth Weight and Gestational Age. The Journal of Paediatrics, 123, 618-624. http://dx.doi.org/10.1016/S0022-3476(05)80965-5

[36] Verkauskiene, R., Figueras, F., Deghmoun, S., Chevenne, D., Gardosi, J. and Levy-Marchal, M. (2008) Birth Weight and Long-Term Metabolic Outcomes: Does the Definition of Smallness Matter? Hormone Research in Paediatrics, 70, 309-315. http://dx.doi.org/10.1159/000157878

[37] Von Ehrenstein, O.S., Mikolajczyk, R.T. and Zhang, J. (2009) Timing and Trajectories of Fetal Growth Related to Cognitive Development in Childhood. American Journal of Epidemiology, 170, 1388-1395. http://dx.doi.org/10.1093/aje/kwp296

[38] Shanmugaraja, V., Kumarasiri, S.G., Wahalawatte, S.L., Wanigasekara, R.V., Begam, P., Jayasinghe, P.K.C.L., Padeniya, T. and Dias, T. (2013) Sri Lankan Fetal/ Birth Weight Charts: Validation of Global Reference for Fetal Weight and Birth Weight Percentiles. Ceylon Medical Journal, 58, 62-65. http://dx.doi.org/10.4038/cmj.v58i2.5681

[39] WHO (1995) Physical Status: The Use and Interpretation of Biometry. In: Report of a WHO Expert Committee (WHO Technical Report Series No. 854), World Health Organization Press, Geneva, 121-155.

[40] Leung, T.N., Pang, M.W., Daljit, S.S., Leung, T.Y., Poon, C.F., Wong, S.M. and Lau, T.K. (2008) Fetal Biometry in Ethnic Chinese: Biparietal Diameter, Head Circumference, Abdominal Circumference and Femur Length. Ultrasound in Obstetrics \& Gynecology, 31, 321-327. http://dx.doi.org/10.1002/uog.5192

\section{Submit or recommend next manuscript to SCIRP and we will provide best service for you:}

Accepting pre-submission inquiries through Email, Facebook, Linkedin, Twitter, etc

A wide selection of journals (inclusive of 9 subjects, more than 200 journals)

Providing a 24-hour high-quality service

User-friendly online submission system

Fair and swift peer-review system

Efficient typesetting and proofreading procedure

Display of the result of downloads and visits, as well as the number of cited articles

Maximum dissemination of your research work

Submit your manuscript at: http://papersubmission.scirp.org/ 